\title{
Gender Power Inequality and Continued Sexual Risk Behavior among Racial/Ethnic Minority Adolescent and Young Adult Women Living with Hiv
}

\section{Nancy Van Devanter ${ }^{1 *}$, Alexandra Duncan ${ }^{2}$, Jeffrey Birnbaum ${ }^{3}$, Tiphani Burrell-Piggott ${ }^{4}$ and Karolynn Siegel ${ }^{5}$}

${ }^{1}$ Associate Professor, New York University, College of Nursing, 726 Broadway, Room 1049, New York, USA ${ }^{2}$ Post-Doctoral Fellow, Johns Hopkins University Bloomberg School of Public Health, Department of Mental Health ,111 Market Place, Suite 850 , Room 8541, Baltimore, USA

${ }^{3}$ Associate Professor, SUNY Downstate Medical Center, Department of Pediatrics \& Master of Public Health Program, 450 Clarkson Avenue, Box 1241, Brooklyn, USA ${ }^{4}$ Columbia University Mailman School of Public Health, Department of Sociomedical Sciences, 722 W. 168th Street, 5th Floor, New York, USA

${ }^{5}$ Professor, Columbia University Mailman School of Public Health, Center for the Psychosocial Study of Health \& IIIness, 722 W. 168 th Street, Room 909, New York, USA

\begin{abstract}
Adolescent and young adult minority women account for approximately $20 \%$ of new cases of HIV in this age group each year in the United States. It is vital to understand factors that influence sexual risk behavior in this population in order to prevent secondary transmission of HIV. As part of a larger qualitative study of youths living with HIV, in- depth interviews were conducted with 26 Black and Latina young women aged 16 to 24 years, infected with HIV through heterosexual transmission. The study explored factors related to continued unprotected sex with male partners. Since learning of their HIV infection, 23\% reported multiple episodes of unprotected vaginal and/or anal sex, $27 \%$ reported condom use for some but not all of the time, $42 \%$ reported condom use all of the time and $7 \%$ were not sexually active. Among the highest risk participants partner refusal to use a condom, having the same HIV sero-status as partner, negative attitudes toward condoms, beliefs about HIV transmission, and fear of disclosure to new partners were associated with risky sex. The data suggests that more research is needed to develop more intensive interventions that address the role of gender power inequity for this sub-set of young women living with HIV.
\end{abstract}

Keywords: AHIV/AIDS; Gender power inequality; Sexual behavior; Adolescents; Young adults with HIV

Abbreviations: HIV: Human Immunodeficiency Virus; AIDS: Acquired Immune Deficiency Syndrome; GED: General Educational Development; HAART: Highly Active Anti-Retroviral Therapy

\section{Introduction}

In 2009, the World Health Program on AIDS reported that adolescents and young adults age 15-24 constituted half of all new cases of HIV worldwide [1]. In the United States in 2009, close to 7,000 new cases of HIV were diagnosed in youth aged 13-24 in states with mandatory reporting for HIV, representing an increase of $16 \%$ of new cases over those reported in 2006 [2]. Young women accounted for $20 \%$ of cases. Minority youth have been disproportionately affected by HIV/AIDS in the U.S. with African Americans and Latinos accounting for $65 \%$ and $15 \%$ respectively of all reported cases in this age group [3]. This racial/ethnic disparity is even more dramatic among young women aged $13-24$, where more than $85 \%$ of those diagnosed with HIV/AIDS are African American and Latina [3]. Despite the growing number of adolescent and young adult women with HIV, they are an understudied population.

The vast majority of adolescents and young adults with HIV have acquired it through sexual transmission [4]. Among young women, heterosexual transmission is the most common cause of HIV infection [4]. Several studies of male and female youths living with HIV have found that while many reduced risky behaviors after learning of their HIV infection, $40 \%$ to $70 \%$ continued to have unprotected sex some or most of the time after their HIV diagnosis [5-8], thus putting them at risk for sexually transmitted infections [9], unintended pregnancy $[10,11]$, new infection with drug resistant strains of HIV $[12,13]$, and increasing the risk of secondary HIV transmission to their uninfected sexual partners $[8,14]$.

Though there are few studies of adolescent and young adult women living with HIV, several studies of adult women with HIV have found evidence of inconsistent condom use post diagnosis, in part due to difficulty negotiating condom use with their male partners [15-17]. Further, a recent qualitative study of 64 African-American adolescent and young adult women at risk for HIV found high rates of partner abuse associated with unprotected sex [18]. More than half of the participants reported having had vaginal sex without a condom despite their desire to have their partner use one as a result of threats or actual physical and/or sexual abuse, emotional abuse/manipulation or partner removing the condom during intercourse. In addition, about one quarter of participants indicated they had not been able to talk to their partner about their wish to use condoms even though they wanted to do so [18]. Other studies of young women at risk for HIV have found those who were able to communicate with male partners about condom use were more likely to use condoms than those who had difficulty communicating [19-22].

Research on young women living with HIV suggests that they may face similar challenges related to partner negotiation to reduce sexual risk behaviors as young women at risk for HIV. A recent study of HIV positive female youths found a history of victimization was associated

${ }^{*}$ Corresponding author: Nancy Van Devanter, DRPH, MPH, EdM, RM, Associate Professor, New York University, College of Nursing , 726 Broadway, Room 1049, New York, NY 10003, USA, Tel: 212.998.5328 ; Fax 212.995.4561; E-mail: nvd2@ nyu.edu

Received October 20, 2011; Accepted December 02, 2011; Published December 20, 2011

Citation: Van Devanter N, Duncan A, Birnbaum J, Burrell-Piggott T, Siegel K (2011) Gender Power Inequality and Continued Sexual Risk Behavior among Racial/Ethnic Minority Adolescent and Young Adult Women Living with Hiv. J AIDS Clinic Res S1:003. doi:10.4172/2155-6113.S1-003

Copyright: @ 2011 Van Devanter N, et al. This is an open-access article distributed under the terms of the Creative Commons Attribution License, which permits unrestricted use, distribution, and reproduction in any medium, provided the original author and source are credited. 
with difficulty in sexual communication and inconsistent condom use [16]. Further, the age of partners of young women living with HIV tend to be older than non-infected young women, thus making condom negotiation more difficult [23].

As the proportion of new HIV cases among adolescents and young adults continues to grow, it is critical to understand factors that influence continued sexual risk behavior among this population. The qualitative study presented here aims to address that gap by exploring the context of risky sexual behavior among adolescent and young adult women living with sexually acquired HIV.

\section{Gender and power imbalance in sexual risk behavior}

The influence of partner characteristics on condom use has been of considerable interest to HIV researchers studying the role of gender and power in sexual behavior [16,19], [24-27], particularly, the ability of women to negotiate condom use or refuse to have sex without a condom [28,29] with their (often older) male partners [30].

Drawing on earlier work in sexual inequality, Connell [31] developed an integrated theory about the role of gender and power that is composed of three social structures: sexual division of labor, sexual division of power, and cathexis. The sexual division of labor stems from cultural norms that limit women to certain occupations, placing them at a disadvantage to men. Sexual division of power refers to gender differences in the ability to exercise influence over others or to create change. Cathexis incorporates the social norms that influence sexual role behavior in society as well as the affective (emotional) attachments women have. Wingood and DiClemente [32] posit that in Connell's model [31] these overlapping social structures have significant implications for health outcomes of women, specifically, their vulnerability of acquiring HIV because of increased exposures, risk factors, and biological risks. Sexual division of labor may lead to economic exposures such as lower education levels, under or unemployment, poverty, and lack of health insurance. Sexual division of power exposures and risk factors include history of physical or sexual abuse, partner resistance to condom use, having a high risk of a partner with HIV, limited access to HIV education, history of drug or alcohol use, limited negotiation skills for condom use. Social norms and affective attachments exposures and risk factors include having a relationship with an older male partner, family cultural influence, negative beliefs about condoms, and depression. Several empirical studies of adult women at risk for HIV provide support their hypothesis.

Much of the recent research on gender power inequalities and HIV has been conducted with women in South Africa where studies have shown decreased ability to negotiate condom use with male partners to be associated with variables related to gender power inequalities including economic dependence, history of abuse, having male partners more than ten years older [33,34], low perceived relationship control [35], and being in a relationship with males that were dominant and controlling [36].

In U.S. studies of women without HIV, a similar relationship between adult women's sexual power and condom use was observed. A study of predominately Latinas found lower condom use was predicted by perceived power imbalance [37]. Further, a recent study of Latinas found those who reported low relationship power were five times less likely to use a condom compared to women reporting high relationship power [27]. Similarly, research by Gutierrez and colleagues [24] on adolescents age 14-19 found that adolescent females perceived themselves as having less influence over relationship decision-making than adolescent males. These researchers suggest that the perception of decreased interpersonal power hinders young women from effectively negotiating safer sex with their partners. To our knowledge, no qualitative studies have explored the issue of gender power inequalities in the context of continued sexual risk behavior of adolescent and young adult women living with HIV. The narratives presented below provide insight into the complex interaction of relational factors and psychosocial vulnerabilities these young women experience.

\section{Materials and Methods}

\section{Study design and participants}

The qualitative data presented here on continued high risk sexual behavior among female adolescent and young adults with sexually acquired HIV were collected as part of a larger, exploratory, primarily qualitative study designed to examine the experiences of AfricanAmerican and Latino adolescents and young adults living with sexually acquired HIV. The principal aims of that study were to examine the illness related adaptative tasks and coping responses of youths living with HIV. A purposive sample of 59 youths ( 26 female) was recruited for the larger study from five well known adolescent HIV specialty clinics located throughout the New York metropolitan area. A representative case sampling method was used in which cases were chosen because they were representative, that is, shared important characteristics (including race and ethnicity) typical of the behaviorally-infected adolescent and young adult population. All recruitment sites provided comprehensive specialty medical, mental health and supportive ancillary social services to adolescents and young adults with HIV. Eligibility criteria included being 13 to 24 years old, previously testing positive for HIV (verified by referring clinics), being cognitively competent to participate, and having acquired HIV infection via unprotected sex or injection drug use. Inclusion criteria for the study presented here is that of the parent study plus female sex, thus the sample consisted of all 26 adolescent and young adult women.

Potential participants were all recruited at the time of their regularly scheduled clinic visits by clinical staff or by study staff. There were no differences between clinical staff and study staff in response rates or demographic characteristics of participants recruited. No refusals were reported among the convenience sample approached; however, a few individuals that agreed to participate dropped out of care and did not complete the interview. The study was approved by Columbia University and New York University Institutional Review Boards, the Institutional Review Boards of collaborating institutions, and received a Federal Certificate of Confidentiality.

\section{Data collection and measures}

Data collection consisted of a focused qualitative interview [38] and a brief quantitative survey to gather demographic and behavioral data. Baseline descriptive quantitative data were collected using audio computer-assisted self interviews (ACASI). In-depth semi-structured, qualitative interviews focused on the individual's experience of living with HIV. An interview guide organized around topic areas related to the study aims was used to structure the interview. Interviewers were graduate students in the fields of public health and social sciences with prior interviewing experience. An intensive, three-day interview training was provided for all of the interviewers by one of the investigators (HML), an expert in qualitative methods, and review of transcripts and periodic meetings with the interviewers took place to insure high quality of the interview data.

Quantitative socio-demographic data collected included age, gender, racial/ethnic identity, education, work status, and age at HIV 
Citation: Van Devanter N, Duncan A, Birnbaum J, Burrell-Piggott T, Siegel K (2011) Gender Power Inequality and Continued Sexual Risk Behavior among Racial/Ethnic Minority Adolescent and Young Adult Women Living with Hiv. J AIDS Clinic Res S1:003. doi:10.4172/2155-6113.S1-003

Page 3 of 7

diagnosis. Sexual behavior and substance use items were taken from the Youth Risk Behavior Survey [39]. To measure sexual behavior, participants were asked "How old were you when you had sexual intercourse for the first time?"; "How many lifetime sexual partners have you had?" (response categories: 1 though 6 or more); "How many sexual partners have you had in the last three months?"; "Did you use drugs or alcohol before your most recent sexual intercourse?"; and "Did you use a condom the last time you had sexual intercourse?" In addition, participants were asked, since HIV diagnosis "What is your best estimate for your percentage of vaginal and anal sex acts unprotected by condoms with HIV-negative partners?" Participants were also asked about lifetime and current use of alcohol, marijuana, and any form of cocaine (powder, crack, or freebase) and any use of heroin, methamphetamines, Ecstasy, and steroids. To assess injection drug use, participants were asked, "During your life, how many times have you used a needle to inject any illegal drug into your body?"

In-depth, focused, semi-structured interviews explored participants' background and experiences prior to HIV infection, as well as domains important to the aims of the study. Specific topics related to sexual behavior since learning of HIV diagnosis included whether the participant had any sexual partner (main or steady, casual, anonymous, or one-night stand), the gender of that partner, the number of each kind of sexual partner, what kind of sex was had with each kind of sexual partner (vaginal, anal, oral), how often condoms were used with each kind of sexual partner, and the frequency of condom use (all of the time, most of the time, rarely or never and in what circumstances for vaginal sex, for oral sex, and for anal sex) with each sexual partner (male, female, transgender).

\section{Data analysis}

Descriptive statistics for the personal demographic variables and sexual risk behavior items were calculated using Stata Statistical Software Release 9.0. Frequencies and cross-tabulations were calculated for categorical variables; means and standard deviations were calculated for continuous variables. Audio-taped qualitative interviews were transcribed verbatim. After an initial review of transcripts by the research team, a preliminary coding scheme was developed that included primary codes related to the analytic foci of the study and sub-codes that specified specific dimensions of primary codes. Content analysis utilizing a constant comparison approach was utilized in analyzing the data [40]. The research team compared variations within and across themes to further refine the coding scheme. The coding scheme facilitated the systematic identification of analytic patterns that became apparent from the data, as well as theoretically important concepts. In addition to overall data coding, a profile of each participant was developed that summarized demographic characteristics and findings related to the primary themes. Further description of data analysis has been presented elsewhere [41]. Themes related to the analysis presented here were sexual behavior, the environment in which sexual behavior occurred, substance use in the context of sexual behavior, and the relationship between sexual partners. All interviews were coded and entered into a database utilizing the qualitative data analysis software, ATLAS.ti ${ }^{\oplus}$ version 4.2. Transcripts were then independently coded by two coders (Kappa .85). Coding inconsistencies were resolved through discussion with the research team.

To analyze qualitative sexual risk behavior data, the following definitions were developed: (1) high-risk participants: reported their condom use as "some of the time" or used condoms with selected partners only; (2) moderate-risk participants: reported condom use "usually but not always"; (3) low-risk participants: reported condom use all of the time; (4) no-risk participants: reported no sexual activity for the last three months.

\section{Results}

The sample for the analysis presented here were 26 adolescent and young adult women with HIV. All study participants contracted HIV through heterosexual transmission. Table 1 describes the participant demographics, time since diagnosis, and highly active anti-retroviral therapy (HAART) for participants. The mean age of participants was 21 years old (range 16 to 24 years). The mean age at time of diagnosis was 18 years old (range 15-23). Two thirds (65\%) of the sample were African-American, 23\% were Latina and $12 \%$ were of other race or ethnicity. About one-third of the young women were enrolled in school at the time of the study (31\%). Many of the participants (39\%) had not graduated from high school or acquired a GED. Only $19 \%$ were currently employed and a little more half of those had a full time job (12\%). About $62 \%$ of participants reported currently being on highly active anti-retroviral treatment.

\section{Sexual behavior}

Sexual behavior from the quantitative survey is presented in Table

\begin{tabular}{|l|l|l|}
\hline \multicolumn{1}{|c|}{ Characteristics } & N & $\begin{array}{l}\% \text { (unless } \\
\text { otherwise } \\
\text { noted) }\end{array}$ \\
\hline $\begin{array}{l}\text { Mean Age at time of interview (Standard Deviation) } \\
\text { [Range] }\end{array}$ & 26 & $\begin{array}{l}20.9 \text { years } \\
(1.9)[16-24]\end{array}$ \\
\hline Mean Age at diagnosis (Standard Deviation)[Range] & 25 & $\begin{array}{l}18.3 \text { years } \\
(1.8)[15-23]\end{array}$ \\
\hline $\begin{array}{l}\text { Mean No. Months since diagnosis (Standard Deviation) } \\
\text { [Range] }\end{array}$ & 26 & $\begin{array}{l}30.2 \text { months } \\
(26.8)[4-104]\end{array}$ \\
\hline Currently on HAART & & \\
\hline Yes & 16 & $61.5 \%$ \\
\hline No & 10 & $38.5 \%$ \\
\hline Race/Ethnicity & & \\
\hline Black/African American Non-Hispanic/Latina & 17 & $65.4 \%$ \\
\hline Hispanic/Latina & 6 & $23.1 \%$ \\
\hline Other Non-Hispanic/Latina & 3 & $11.5 \%$ \\
\hline Educational Attainment at time of interview & & \\
\hline Less than HS/Some HS & 10 & $38.5 \%$ \\
\hline HS Diploma/GED & 10 & $38.5 \%$ \\
\hline Some College/Associates Degree & 5 & $19.2 \%$ \\
\hline College Graduate & 1 & $3.8 \%$ \\
\hline Employment Status at time of interview & & \\
\hline Full-time & 3 & $11.5 \%$ \\
\hline Part-time & 2 & $7.7 \%$ \\
\hline Not employed & 21 & $80.8 \%$ \\
\hline
\end{tabular}

Table 1: Demographic and Treatment Characteristics of Adolescent and Young Adult Women with HIV.

\begin{tabular}{|l|l|l|}
\hline Sexual Behavior Characteristics & N & Percent \\
\hline Sexual Behavior Pre HIV Diagnosis & \multicolumn{2}{l|}{} \\
\hline Sex at age 11 or younger & 4 & $15.3 \%$ \\
\hline Six or more lifetime sexual partners & 17 & $65.3 \%$ \\
\hline Sexual Behavior Post HIV Diagnosis (Last 3 Months) & \\
\hline 2 or more sexual partners in last 3 months & 20 & $76.9 \%$ \\
\hline Condom used last vaginal/anal sex & 21 & $80.7 \%$ \\
\hline Used Alcohol or drugs at last sex & 2 & $7.6 \%$ \\
\hline Sexual Identity & & \\
\hline Heterosexual & 21 & $80.7 \%$ \\
\hline Bisexual & 5 & $19.2 \%$ \\
\hline
\end{tabular}

Table 2: Sexual Behavior of Adolescent and Young Adult Women with HIV. 
2. About $15 \%$ of females reported having their first sexual intercourse before the age of 11 and $65 \%$ reported 6 or more life time sexual partners. Over three quarters (77\%) reported two or more sexual partners during the last three months; $81 \%$ reported using a condom for vaginal or anal sex the last time they had sexual intercourse and about $8 \%$ reported use of alcohol of drugs the last time they had sex. Most (81\%) self-identified as heterosexual and $19 \%$ as bisexual.

Qualitative data provided more nuanced information on sexual behavior among participants (Table 3). When asked about sexual behavior with their current sexual partner about $8 \%(\mathrm{~N}=2)$ reported they were not sexually active (no risk), $42 \%(\mathrm{~N}=11)$ reported condom use every time for vaginal or anal sex and having fewer than three sexual partners (low risk), 27\% (N=7) reported using condoms most but not all of the time for vaginal and anal sex and having three or more sexual partners (moderate risk), and 23\% ( $\mathrm{N}=6)$ reported multiple episodes of unprotected vaginal or anal sex in the last three months (high risk).

(Table 4) illustrates partner relational characteristics of high risk participants as reported in the qualitative interviews. The primary reason reported for unprotected sex was partner refusal to use a condom (5/6). Among this group half (3/6) of their male partners were more than 10 years older (12 to 15 years) older. In two cases, male partners were positive for HIV infection which also affected condom use; both young women with HIV positive partners reported negative attitudes toward condoms. Female participants having unprotected sex also described their own and/or their partners' inaccurate beliefs about HIV transmission as reasons for unprotected sex. In addition, a few women expressed, fears of rejection by a new partner upon disclosure of HIV thus, they remained with their current partner who refused to wear condoms.

In five out of six cases, women had disclosed their HIV infection to their male partners. One participant, who had not disclosed to any sexual partners, did not report any of the above reasons for continued

\begin{tabular}{|l|l|l|}
\hline Sexual Risk Behavior & N & Percent \\
\hline High Risk & 6 & $23.1 \%$ \\
\hline Moderately High Risk & 6 & $26.9 \%$ \\
\hline Low Risk & 7 & $42.3 \%$ \\
\hline No Current Risk & 11 & $7.7 \%$ \\
\hline
\end{tabular}

${ }^{1}$ Condom use some of the time or with selected partners only for anal and vaginal sex

${ }^{2}$ Condom use usually but not always for anal and vaginal sex

${ }^{3}$ Condom use always for anal and vaginal sex

${ }^{4}$ Not currently sexually active

Table 3: Self Reported Sexual Behavior in Women since HIV Diagnosis - Qualitative Interview Results.

\begin{tabular}{|l|l|l|l|l|l|}
\hline Participant & $\begin{array}{c}\text { Limited } \\
\text { Condom } \\
\text { Negotiation } \\
\text { Skills }\end{array}$ & $\begin{array}{c}\text { Older } \\
\text { Partner }\end{array}$ & $\begin{array}{c}\text { Partner } \\
\text { HIV + }\end{array}$ & $\begin{array}{c}\text { Negative } \\
\text { Condom } \\
\text { Attitudes }\end{array}$ & $\begin{array}{c}\text { HIV } \\
\text { Disclosure } \\
\text { to Partner }\end{array}$ \\
\hline R1 & $\mathrm{X}$ & & & & $\mathrm{X}$ \\
\hline R2 & $\mathrm{X}$ & 15yrs older & $\mathrm{X}$ & $\mathrm{X}$ & $\mathrm{X}$ \\
\hline R3 & $\mathrm{X}$ & & $\mathrm{X}$ & $\mathrm{X}$ & $\mathrm{X}$ \\
\hline R4 & $\mathrm{X}$ & 13 yrs older & & & $\mathrm{X}$ \\
\hline R5 & $\mathrm{X}$ & 12 yrs older & & & $\mathrm{X}$ \\
\hline R6 & & & & & \\
\hline Total & $5 / 6$ & $3 / 6$ & $2 / 6$ & $2 / 6$ & $5 / 6$ \\
\hline
\end{tabular}

$\mathrm{X}$ represents the characteristic being present

Table 4: Partner Relational Characteristics among HIV Positive Adolescent and Young Adult Women with Continued High Risk Sexual Behavior ( $N=6)$. high risk behavior. She indicated that she used condoms with some partners but not with others. However, she did not describe any discernable patterns or partner characteristics that appeared to affect her condom use.

The cases presented below are illustrations of partner relationship dynamics and attitudes toward condoms among adolescent and young women with continued high risk sexual behavior.

\section{Male partner refused to wear condom}

A 22 year old African-American female, who tested positive for HIV at age 17, described her unsuccessful attempts to get her HIV negative boyfriend (age 25) of two years, who knows about her infection, to use condoms for sex. She said she was afraid that she would infect him and was trying to have less sex to reduce that chance. When asked why her boyfriend did not want to use condoms she explained:

“He was just like I love you, I don’t care... I was like - you know, I don't want to give it - he's like I don't care. That day it took like an hour and a half trying to convince him to put that condom on. He was like no, I don't want to, I don't want to and that's how it's been.... I want him to use them all the time but if he don't, what can I do but just keep suggesting it?" (R1)

She said she feels "a little guilty" sometimes. In response to his refusal she expressed a passive acceptance of the situation; "if he's not really caring I'm not really gonna let it stress me out. That's how it is."

Another young woman described her HIV negative boyfriend's resistance to using condoms. Her partner, who is 12 years older, has known about her HIV infection since the beginning of their relationship. She explained that she had made multiple attempts to get him to use condoms. She reported that they only used condoms about $50 \%$ of the time. When asked why they didn't consistently use condoms she responded:

"I do not know why ... I really can't say. He's negative, he know he's negative, he's been tested but he's like ... we've been down this road before. I've argued with him, I've cried - just to try to get him to wear it if - he would put it on and then he would take it off and then I would put it on and then he would pull it out of me - so I don't know" (R5).

\section{Partner HIV status influences sexual behavior}

Two young women who reported partner resistance to using condoms had current partners who were also infected with HIV. Both of these young women reported their partner's HIV positive status influenced their decision to have sex without a condom. One, a 23 year old HIV-infected female, described her perspective on the benefits and risks of unprotected sex with her HIV-infected male partner who refused to use a condom:

"I have like just one sex partner. He's HIV-infected too. Which is even bad but it just feels better you know knowing he already have it, not telling him, you know - because he knew me for a long time so it's like - it's just better. Even though it's dangerous, at the same time because I could get a new strain of HIV". (R3)

Another participant with an HIV infected partner who was 15 years older accepted his refusal to use condoms. She interprets his refusal as evidence that he cares about her: "It's like a comfort likeokay he knows that he's not using them so that means he must care about me...." (R2). 


\section{Both partners have negative attitudes toward condoms}

Both young women with HIV infected partners described above also expressed negative attitudes toward condoms. One said that she, herself, did not like to use condoms because they irritated her and that she was somewhat relieved that her partner did not want to use them. The other young women with an HIV infected partner also expressed negative attitudes toward condoms but said they did not use them because they were too expensive. This couple had been in a relationship for more than 8 years.

Two sub-themes related to acceptance of partner refusal to use condoms were identified in women with HIV negative partners: Beliefs about HIV transmission risk and fear of disclosing HIV status to a new partner.

\section{Inaccurate beliefs about HIV transmission risk influence sexual behavior}

One young woman described her partner's belief that he was protected from HIV by practicing penile withdrawal before ejaculation: "Well for him protection is not coming in me" (R5).

Another young woman who had unprotected sex with two partners described her beliefs about transmission of HIV to her unprotected partners: "neither one of them is positive. I thank God for that...so I pretty much see myself as a carrier and not really a giver. But you never know when that time's gonna happen and somebody can get it" (R1).

A participant whose HIV negative partner refused to use condoms explained "they say it's harder for a man to get it from a woman than for a woman to get it from a man. That's what he said but still." She said she will continue to urge him to use condoms but knows that he won't and she will have sex with him anyway because he is her partner (R4).

\section{Fear of disclosing HIV status to a new partner influences condom use}

Among the young women who had continued unprotected sex, $83 \%(5 / 6)$ had disclosed their HIV status to their current partner. Two of these young women described their fears of disclosing to a new sex partner. One explained:

"If me and my boyfriend don't stay together for some reason, it's not gonna be easy just to have sex with somebody else, especially with my condition. And you know to get to that point with this guy to let him know first my status and then if he's willing to take that step with me, you know maybe it'll happen but other than that I don't see it happening."(R6)

The other young woman described her previous experience of rejection by a new partner:

"Yeah. I don't want to start over. I don't want to explain anything to anybody. That's pretty much it. It's a mistake to be with a negative person even if the person thinks they can deal with it at the beginning... With Joey (pseudonym), the person I was really, really, really trying to be with but towards the end he kind of lost it. He couldn't deal with it for the duration of us being together." (R2)

In contrast to the findings in women with high sexual risk behavior, the problem of partner resistance is reported by only one of the twenty young women in the moderate, low, and no risk group. In that case, the young woman refused to have sex with her HIV negative partner without a condom.

\section{Discussion}

It is important to note that the majority of adolescent and young adult women living with HIV reported use of condoms with their male partners most or all of the time. Just under one quarter of the young women in the present study continue to have unprotected sex with their partners despite receiving advice on sexual risk reduction from their health care providers. This finding is similar to the male participants in the parent study where $26 \%$ reported frequent unprotected sex with their male partners [42].

The qualitative study presented here provides important insights into the dynamics of gender power inequality and condom use among young women living with HIV. Consistent with findings from Sturdevant and colleagues [23], five of six participants who continued to have unprotected sex stated the primary reason was partner refusal to use condoms. Further, male partners were greater than ten years older in half of the cases. These young women expressed concern for their partner's risk of getting HIV and, in the case of sero-concordant couples, to re-infection with HIV themselves. They described significant efforts on their part to get their partners to use condoms. When they were unsuccessful, they acquiesced to their partner's wishes, despite knowing the risk of new infection.

Having a partner who refused to use condoms and was seroconcordant appeared to create additional complexity for young women. Though they were aware of the risk of transmitting a new viral strain to their partners and themselves, they seemed to express some relief in knowing they would not be responsible for their partner becoming infected. It is possible that these young women, living with a stigmatized chronic disease, feel more valued by their partners because of their refusal to use condoms, as one stated "it must mean he cares about me."

Sero-sorting (choosing a partner who is the same HIV status in order to have unprotected sex) has been widely reported in the men who have sex with men community throughout the HIV epidemic [43] and more recently among women [44]. In this study, some participants appeared to be staying in relationships with their HIV infected partners for several reasons including, freedom from worry about infecting a negative partner and feeling accepted and desirable. Fear of having to disclose their sero-status to a new partner and the risk of rejection was also described by participants and may have been a factor in their willingness to agree to their partners refusal to use condoms and to stay in the relationship despite the risks to themselves. HIV stigma has been well documented and it is likely that it influenced the decisions made by young women who were already disadvantaged by gender power inequalities [45].

Some high risk participants provided a rationalization for continued high risk behavior and how to decrease transmission risk. The participants described penile withdrawal before ejaculation, being a "carrier" of HIV and not a source of infection because partners have yet to become infected, and the belief that men are far less likely to "get it from a woman." Health education regarding HIV transmission for young women engaged in care at adolescent focused HIV programs is comprehensive and health literacy among program participants is typically high. However, these data indicate that the gender power dynamics of their relationships may be more powerful in shaping their beliefs about transmission and thus further educational intervention, particularly on relationship dynamics and additional condom negotiation strategies are needed.

Negative attitude about condoms have consistently been 
Citation: Van Devanter N, Duncan A, Birnbaum J, Burrell-Piggott T, Siegel K (2011) Gender Power Inequality and Continued Sexual Risk Behavior among Racial/Ethnic Minority Adolescent and Young Adult Women Living with Hiv. J AIDS Clinic Res S1:003. doi:10.4172/2155-6113.S1-003

Page 6 of 7

demonstrated in other studies of adolescents and adults with HIV and were identified by two participants as barriers to condom use [46,47]. Negative attitudes and beliefs about condoms among the two young women with the highest risk behavior appeared to be influenced by their main male partner's attitudes as well as their own. It is difficult to tell whether negative attitudes toward condoms decreased motivation to use them or were an additional justification for not using them. In either case, studies have shown that interventions can be successful in changing attitudes toward condoms [7]. Additional resources for effective interventions to prevent HIV and sexually transmitted infections among youth with and at risk for HIV are available through the Diffusion of Effective Behavioral Interventions (DEBI) program initiated by the Center for Disease Control and Prevention (CDC). Interventions found to be effective in research studies are available and can be tailored to specific populations (e.g. see www. effectiveinterventions.org).

The role of gender and power dynamics has been recognized for more than a decade as a factor in the increasing rates of HIV infection among women worldwide $[36,48]$. What is striking about the narratives of young women in this study is the complexity of the gender power inequalities that influence their continued sexual risk behavior. They are vulnerable to acquiescing to their partner's desire to have unprotected sex because they want to maintain the relationship and may fear losing the partner if they refuse. In addition, the loss of the partner would require disclosure to a new partner if they want to have a sexual relationship in the future. The partner's willingness to have unprotected sex with them was construed by some of the women symbolically as providing roof of the partner's love and their desirability. This study provides contextual information about the complexity of the gender power dynamics that should be further investigated in quantitative studies to inform development of interventions.

Heterosexual couple intervention studies in adults with HIV have been successful in increasing condom use among participants [49]. Future research should explore the acceptability and feasibility of such approaches with this age group where the often transient nature of relationships and the difficulty of engaging often older male partners in more intensive interventions present significant challenges. Although couples described in this study were aware of the risks of having unprotected sex with an HIV positive partners (i.e. being re-infected with a different and potentially drug resistant strain of HIV), the data presented here suggests that the perceived benefits of unprotected sex outweighed the perceived risks of transmission. Participants having unprotected sex were either not sufficiently convinced of the transmission risks (health literacy), and/or were (in the case of female partners) deferring to their partners' wishes. These issues should be explored further in future research.

\section{Limitations}

The findings of this study must be interpreted within the context of several limitations. This research was designed as a qualitative study and not intended to provide generalizable information about all young women living with HIV. However, the results presented here do address many areas relevant to all young people living with HIV. Study participants were recruited from settings where they were receiving comprehensive HIV medical care, including social support services. Thus, those who are not engaged in such care are not represented. All measures of sexual and substance use behavior were based on self-report and could be subject to social desirability influences. The cross-sectional nature of the data presented limits our ability to assess changes in sexual behavior over time. Despite these limitations, the study findings contribute to the understanding of the factors affecting sexual risk behaviors among adolescents and young adult women with $\mathrm{HIV}$, and thus, have important implications for interventions in this population.

\section{Acknowledgements}

The study was supported by funding from the National Institute for Child Health and Human Development 5 R01HD041891. The authors thank Craig Fryer, Julie Stein, Mary Irvine, Nana Mensah, Amy Bleakley, Sonya Romanoff and Destiny staff of Project STAY New York Presbyterian Hospital, the staff of Project HEAT SUNY Downstate Medical Center, Dr. Linda Levin and the staff of Mount Sina Adolescent Health Program, Dr. Robert Johnson and the staff of UMDNJ Division of Adolescent Young Adult Medicine, and Dr. Donna Futterman and the staff of the Adolescent AIDS Program at Montefiore Ramjohn for their assistance in data collection, transcription, coding, and data management, Dr. Alwyn Cohall and the Medical Center. We would like to express our deep gratitude for the young men and women who shared their experience and insights about living with HIV.

\section{References}

1. United Nations Program on HIVIAIDS (UNAIDS) and World Health Organization (WHO) (2009) AIDS Epidemic Update 2009. Accessed 08/31/10.

2. Centers for Disease Control and Prevention (CDC) (2011) Diagnoses of HIV infection and AIDS in the United States and Dependent Areas, 2009. HIV Surveillance Report, 21. Accessed 10/19/11.

3. Centers for Disease Control and Prevention (CDC) (2011) Disparities in diagnoses of HIV infection between Blacks/African Americans and other racial/ ethnic populations - 37 States, 2005-2008. MMWR, 60: 93-98.

4. Centers for Disease Control and Prevention (CDC) (2011) HIV surveillance in adolescents and young adults. Accessed 10/19/11.

5. Rotheram-Borus MJ, Murphy D, Coleman C, Kennedy M, Reid E, et al. (1997) Risk acts, health care, and medical adherence among HIV+ youths in care ove time. AIDS and Behavior 1: 43-52.

6. Murphy D, Durako SJ, Moscicki AB, Vermund SH, Ma Y, et al. (2001) No change in health risk behavior over time among HIV-infected adolescents in care: Role of psychological distress. J Adolesc Health.. 29: 57-63.

7. Naar-King S, Wright K, Parsons JT, Frey M, Templin T, et al. (2006) Healthy choices: Motivational enhancement therapy for health risk behaviors in HIV positive youths. AIDS Educ Prev 8: 1-11.

8. Koenig LJ, Pals SL, Chandwani S, Hodge K, Abramowitz S, et al. (2010) Sexual transmission risk behavior of adolescents With HIV acquired perinatally or through risky behaviors. J Acquir Immune Defic Syndr 55: 380-390.

9. Diamond C, Buskin S (2000) Continued risky behavior in HIV-infected youth Am J Public Health 90: 115-118.

10. Levin L, Henry-Reid L, Murphy DA, Peralta L, Sarr M, et al. (2001) Incident pregnancy rates in HIV infected and HIV uninfected at-risk adolescents. Adolesc Health 29: 101-108.

11. Koenig LJ, Espinoza L, Hodge K, Ruffo N (2007) Young, seropositive, and pregnant: epidemiologic and psychosocial perspectives on pregnan adolescents with human immunodeficiency virus infection. Am J Obste Gynecol 197: S123-S131.

12. Hecht FM, Grant RM, Petropoulos CJ, Dillon B, Chesney MA, et al. (1998) Sexual transmission of an HIV-1 variant resistant to multiple reversetranscriptase and protease inhibitors. N Engl J Med 339: 307-311.

13. Drumright LN, Frost SD (2008) Sexual networks and the transmission of drug resistant HIV. Curr Opin Infect Dis 21: 644-652.

14. Jennings JM, Ellen JM, Deeds BG, Harris DR, Muenz LR, et al. (2009) Youth living with HIV and partner-specific risk for the secondary transmission of HIV. Sex Transm Dis 36: 439-444

15. Raiford JL, Wingood GM, DiClemente RJ (2007) Correlates of consistent condom use among HIV-positive African American women. Women and Health 46: 41-58.

16. Clum GA, Chung S, Ellen JM, Perez LV, Murphy DA, et al. (2011) Victimization and sexual risk behavior in young, HIV positive women: Exploration of mediators. AIDS Behav.

17. Carrieri MP, Rey D, Serraino D, Trémolières F, Méchali D, et al. (2006) Oral 
Citation: Van Devanter N, Duncan A, Birnbaum J, Burrell-Piggott T, Siegel K (2011) Gender Power Inequality and Continued Sexual Risk Behavior among Racial/Ethnic Minority Adolescent and Young Adult Women Living with Hiv. J AIDS Clinic Res S1:003. doi:10.4172/2155-6113.S1-003

contraception and unprotected sex with occasional partners of women HIVinfected through injection drug use. AIDS Care 18: 795-800.

18. Teitelman AM, Tennille J, Bohinski JM, Jemmott LS, Jemmott JB (2011) Unwanted unprotected sex: Condom coercion by male partners and selfsilencing of condom negotiation among adolescent girls. ANS Adv Nurs Sci 34: 243-259.

19. DePadilla L, Windle M, Wingood G, Cooper H, DiClemente R (2011) Condom use among young women: Modeling the theory of gender and power. Health Psychol 30: 310-319

20. Swenson RR, Rizzo CJ, Brown LK, Vanable PA, Carey MP, et al. (2010) HIV knowledge and its contribution to sexual health behaviors of low-income African American adolescents. J Natl American Med Assoc 102: 1173-1182.

21. Seth P, Raiji PT, DiClemente RJ, Wingood GM, Rose E (2009) Psychological distress as a correlate of a biologically confirmed STI, risky sexual practices, self-efficacy and communication with male sex partners in African-American female adolescents. Psychol Health Med 14: 291-300.

22. Kann L, Olsen EO, McManus T, Kinchen S, Chyen D, et al. (2011) Sexual identity, sex of sexual contacts, and health-risk behaviors among students in grades 9-12--youth risk behavior surveillance, selected sites, United States, 2001-2009. MMWR Surveill Summ. 60: 1-133.

23. MMWR Early Release 60:29-33.

24. Sturdevant MS, Belzer M, Weissman G, Friedman L, Sarr M, et al. (2001) The Relationship of unsafe sexual behavior and the characteristics of sexual partners of HIV infected and HIV uninfected adolescent females. J Adolesc Health 29S: 64-71.

25. Gutierrez L, Oh HJ, Gillmore MR (2000) Toward an understanding of empowerment for HIVIAIDS prevention with adolescent women. Sex Roles 42: 581-611.

26. Amaro H, Raj A (2000) On the margin: Power and women's HIV risk reduction strategies. Sex Roles 42: 723-749.

27. Harvey SM, Bird ST, Galvotti C, Duncan EA, Greenberg D (2002) Relationship power, decision making, and condom use among women at risk for HIVISTDs. Women Health 36: 69-83

28. Pulerwitz J, Amaro H, De Jong W, Gortmaker SL, Rudd R (2002) Relationship power, condom use and HIV risk among women in the USA. AIDS Care 14: 789-800.

29. East L, Jackson D, O’Brien L, Peters K (2011) Condom negotiation: experiences of sexually active young women. J Adv Nurs 67: 77-85.

30. Salazar LF, DiClemente RJ, Wingood GM, Crosby RA, Harrington K, et al. (2004) Self-concept and adolescents' refusal of unprotected sex: a test of mediating mechanisms among African American girls. Prev Sci 5: 137-149.

31. Bralock AR, Koniak-Griffin D (2007) Relationship, power, and other Influences on self-protective sexual behaviors of African American female Adolescents. Health Care Women Int 28: 247-267.

32. Connell RW (1987) Gender and Power. Stanford, CA, Stanford University Press.

33. Wingood GM, DiClemente RJ (2000) Application of the Theory of Gender and Power to examine HIV-related exposures, risk factors, and effective interventions for women. Health Educ Behav 27: 539-565.

34. Langen TT (2005) Gender power imbalance on women's capacity to negotiate self-protection against HIVIAIDS in Botswana and South Africa. Afr Health Sci 5: 188-197.

35. Greig FE, Koopman C (2003) Multilevel analysis of women's empowerment and HIV prevention: Quantitative survey results from a preliminary study in Botswana. AIDS Behav 7: 195-208.

36. Pettifor AE, Measham DM, Rees HV, Padian NS (2004) Sexual power and HIV risk, South Africa. Emerg Infect Dis 10: 1996-2004.

37. Dunkle KL, Jewkes RK, Brown HC, Gray GE, Mclntyre JA, et al. (2004) Gender based violence, relationship power, and risk of HIV infection in women attending antenatal clinics in South Africa. Lancet 363: 1415-1421.

This article was originally published in a special issue, Risk Behaviour handled by Editor(s). Dr. Karl Peltzer, Human Science Research Institute, South Africa.
38. Gomez CA, VanOss Martin B (1996) Gender, culture, and power: Barriers to HIV-prevention strategies for women. Journal of Sex Research 33: 353-362.

39. Merton RK, Fiske M, Kendall PL (1956) The Focused Interview. Glencoe, Free Press.

40. Centers for Disease Control and Prevention (CDC) (2002) Handbook for conducting youth risk behavior surveys. Atlanta, GA: US Department of Health and Human Services, CDC, National Centers for Chronic Disease Prevention and Health Promotion.

41. Corbin J, Strauss A (2008) Basics of Qualitative Research. Thousand Oaks Sage.

42. Siegel KH, Lekas HM, Olson K, VanDevanter N (2010) Gender, sexua orientation, and adolescent HIV testing: a qualitative analysis. J Assoc of Nurses AIDS Care 21: 314-326.

43. VanDevanter N, Duncan A, Burrell-Piggott T, Bleakley A, Birnbaum J, et al (2011) The influence of substance use, social sexual environment, psychosocial factors, and partner characteristics on high-risk sexual behavior among young Black and Latino men who have sex with men living with HIV. A qualitative study. AIDS Patient Care STDs 25: 113-121.

44. Semple SJ, Patterson TL, Grant I (2000) Partner type and sexual risk behavior among HIV positive gay and bisexual men: social cognitive correlates. AIDS Educ Prev 12: 340-356.

45. Liu C, Hu H, Goparaju L, Plankey M, Bacchetti P, et al. (2011) Sexual serosorting among women with or at risk of HIV infection. AIDS Behav 15: 9-15.

46. Valdiserri RO (2002) HIVIAIDS stigma: An impediment to public health Editorial. Am J Public Health 92: 341-342.

47. Crepaz N, Marks G (2002) Towards an understanding of sexual risk behavior in people living with HIV: A review social, psychological, and medical findings. AIDS 16: 135-149.

48. Rice E, Batterham P, Rotheram-Borus MJ (2006) Unprotected sex among youth living with HIV before and after the advent of highly active antiretroviral therapy. Perspect Sex Reprod Health 38: 162-167.

49. Persson A, Richards W (2008) Vulnerability, gender and "proxy negativity": Women in relationships with HIV-positive men in Australia. Soc Sci Med 67: 799-807.

50. El-Bassel N, Witte SS, Gilbert L, Wu E, Chang M, et al. (2005) Long-term effects of an HIV/STI sexual risk reduction intervention for heterosexual couples. AIDS Behav 9: 1-13. 